\title{
Phytoprotection
}

\section{Interactions between Pythium tracheiphilum, Meloidogyne hapla and Pratylenchus penetrans on lettuce}

\author{
J.A. Gracia, R.D. Reeleder et G. Bélair
}

Volume 72, numéro 3, 1991

URI : https://id.erudit.org/iderudit/706010ar

DOI : https://doi.org/10.7202/706010ar

Aller au sommaire du numéro

Éditeur(s)

Société de protection des plantes du Québec (SPPQ)l

ISSN

0031-9511 (imprimé)

1710-1603 (numérique)

Découvrir la revue

Citer cet article

Gracia, J., Reeleder, R. \& Bélair, G. (1991). Interactions between Pythium tracheiphilum, Meloidogyne hapla and Pratylenchus penetrans on lettuce. Phytoprotection, 72(3), 105-114. https://doi.org/10.7202/706010ar
Résumé de l'article

La croissance des plants de laitue (Lactuca sativa) en cabinet de croissance a été diminuée par la présence des Pythium tracheiphilum, Meloidogyne hapla et Pratylenchus penetrans. Une diminution additive marquée de la croissance de la laitue a été observée lorsque les $P$. tracheiphilum et $M$. hapla ont été ajoutés au sol simultanément. Une diminution additive a été observée lorsque le $P$. penetrans et une faible population du F. tracheiphilum ont été combinés. Par contre, lorsqu'une forte population du $P$. tracheiphilum était présente, les dommages observés n'ont pas augmenté significativement et une interaction négative a été observée. Le champignon a eu un effet négatif sur la population des deux espèces de nematode dans la racine. 


\title{
Interactions between Pythium tracheiphilum, Meloidogyne hapla and Pratylenchus penetrans on lettuce
}

\author{
J.A. Gracia \\ Department of Plant Science, Macdonald College of McGill University, \\ 21111 Lakeshore Rd., Sainte-Anne-de-Bellevue, Québec, Canada, H9X 1CO
}

\author{
R.D. Reeleder ${ }^{1}$ \\ Agriculture Canada, Research Station, P.O. Box 186, \\ Delhi, Ontario, Canada, N4B 2W9 \\ I. To whom correspondence should be addressed. \\ G. Bélair \\ Agriculture Canada, Research Station, 430 Gouin Blvd., \\ Saint-Jean-sur-Richelieu, Québec, Canada, J3B 3E6
}

(Received 1991-04-25; accepted 1991-12-13)

\begin{abstract}
The growth of lettuce plants (Lactuca sativa) was reduced by Pythium tracheiphilum, Meloidogyne hapla and Pratylenchus penetrans under growth chamber conditions. A marked additive decrease in lettuce growth was observed when $P$. tracheiphilum and $M$. hapla were added to the soil simultaneously. Interactions between $P$. penetrans and $P$. tracheiphilum, however, were additive at low populations of $P$. tracheiphilum, but appeared to be negative at high populations of the fungus. The fungus had a negative effect on the populations of both species of nematode in roots.
\end{abstract}

Gracia, J.A., R.D. Reeleder, and G. Bélair. 1991. Interactions between Pythium tracheiphilum, Meloidogyne hapla and Pratylenchus penetrans on lettuce. PHYTOPROTECTION 72:105-114.

La croissance des plants de laitue (Lactuca sativa) en cabinet de croissance a été diminuée par la présence des $P y t h i u m$ tracheiphilum, Meloidogyne hapla et Pratylenchus penetrans. Une diminution additive marquée de la croissance de la laitue a été observée lorsque les $P$. tracheiphilum et $M$. hapla ont été ajoutés au sol simultanément. Une diminution additive a été observée lorsque le $P$. penetrans et une faible population du $P$. tracheiphilum ont été combinés. Par contre, lorsqu'une forte population du $P$. tracheiphilum était présente, les dommages observés n'ont pas augmenté significativement et une interaction négative a été observée. Le champignon a eu un effet négatif sur la population des deux espèces de nématode dans la racine.

\section{Introduction}

A disease of lettuce (Lactuca sativa L.) causing a severe wilting and death of infected plants was observed in the muck soil region of Québec in 1983 and was consistently associated with the presence of the fungus Pythium tracheiphilum Matta(Reeleder etal. 1985). First described in 1965 in Italy (Matta 1965) and subsequently found in other parts of Europe, it also has caused considerable losses in the United States (Tortolero and Sequeira 1978). In Québec, losses vary from field to field and year to year with a range from $0-24 \%$ (Reeleder and Charbonneau 1987). Typical above-ground symptoms are stunting and wilting of the plant. A reddish-brown discoloration of the vascular tissue of the tap root results from colonization of the tissue by $P$. tracheiphilum. Infected plants

$\overline{0031-9511 / 91 \$ 1.00+.10}$ generally die before mid-season. The disease tends to be more severe in years of high precipitation and in areas with poor drainage. Weather conditions prevailing during the spring-seeded lettuce crop are more favorable for the disease than weather during summer plantings (Reeleder and Charbonneau 1987).

Presently there is little information available regarding the ecology of $P$. tracheiphilum. In Québec muck soils, plant parasitic nematodes are often associated with diseased vegetable crops. The northern root-knot nematode, $\mathrm{Mel}$ oidogyne hapla Chitwood, and the lesion nematode, Pratylenchus penetrans (Cobb) Filipjev and Schuurmans-Stekhover, are the most common species recovered from lettuce fields (Vrain and Dupré 1982). Populations of M. hapla in muck soil vegetable fields in southwestern Québec ranged from 1 to 550 per $100 \mathrm{~cm}^{3}$ of soil. Populations of Pratylenchus spp. in these fields ranged from 2 to 235 per $100 \mathrm{~cm}^{3}$ (Vrain and 
Dupré 1982). These genera of nematodes have been reported as increasing or suppressing the activity of certain species of $P$ ythium either by providing an entrance to the root system or by physiological effects on the host (Melendéz and Powell 1970a; Holtzmann and Santo 1971). Previous work with $P$. tracheiphilum suggests that wounding the root system increases the severity of the disease (Tortolero and Sequeira 1978; R.D. Reeleder, unpublished data). Wounding of roots by nematodes therefore may be a factor in root colonization by the fungus. The objective of this study was to investigate the nature of the interactions between $P$. tracheiphilum and two species of plant parasitic nematode: $M$. hapla and $P$.penetrans.

\section{Materials and methods}

Interactions between $M$. hapla and $\boldsymbol{P}$. tracheiphilum. Lettuce cv. Ithaca was seeded into plastic trays containing vermiculite which then were placed on a growth bench with a photoperiod of $16 \mathrm{~h}$, a light intensity of approximately $250 \mu \mathrm{mol} /\left(\mathrm{m}^{2} \cdot \mathrm{s}\right)$, and temperatures of $24^{\circ} \mathrm{C}$ (day) and $15^{\circ} \mathrm{C}$ (night). Trays were watered daily and fertilized weekly with Plant-Pro 20-20-20 (Plant Products Co. Ltd., Bramalea, Ont.), at a rate of $2.5 \mathrm{~g} / \mathrm{L}$ of water. Two-weekold seedlings were used in all experiments.

Nematode populations were obtained as follows. Tomatoes (Lycopersicon esculentum Mill) cv. Rutgers were grown in muck soil naturally infested with $M$. hapla and kept for 4 months in a greenhouse at $24 \pm 4^{\circ} \mathrm{C}$ with a photoperiod of $14 \mathrm{~h}$. To estimate egg populations in tomato roots, $10 \mathrm{~g}$ of infected roots were chopped into $1-2 \mathrm{~cm}$ pieces and stirred for $3 \mathrm{~min}$ with a $0.5 \%$ sodium hypochlorite solution (Javex, Bristol-Myers Products Canada Inc. Toronto, Ont.) to dissolve egg mass matrices. The suspension then was passed through a series of sieves with openings of $1.00 \mathrm{~mm}, 710$ $\mu \mathrm{m}, 90 \mu \mathrm{m}$ and $25 \mu \mathrm{m}$. Eggs collected on the $25-\mu \mathrm{m}$ sieve were rinsed in a stream of tap water and counted on a small plastic dish with a grid on the bottom.

A pasteurized soil mixture [4:1 muck:sand $(\mathrm{v} / \mathrm{v})$; steamed at $70-80^{\circ} \mathrm{C}$ for $\left.30 \mathrm{~min}\right]$ was infested with sufficient pieces of nematodeinfected tomato roots to reach densities of 0,1250 , and $4063 \mathrm{eggs} / 100 \mathrm{~cm}^{3}$ of soil $(0,4000$ and 13000 eggs/12.7-cm-diam. pot). The soil was kept in trays $(35 \mathrm{~cm} \times 30 \mathrm{~cm}$ $\times 14 \mathrm{~cm})$ and water was added $(100 \mathrm{~mL} / \mathrm{kg}$ soil $)$ to maintain moist conditions, allowing roots to decompose and eggs to hatch. Trays were enclosed within plastic bags and held on a growth bench at $24^{\circ} \mathrm{C}$ (day) and $15^{\circ} \mathrm{C}$ (night) with a photoperiod of $16 \mathrm{~h}$. After 2 weeks, a sample of infested soil was taken and estimates were made of nematode populations, using the Baermann pan technique (Barker 1985). Populations at this time had reached the desired levels for inoculation of the lettuce seedlings.

Sporangia of $P$. tracheiphilum (isolate LW 7) were obtained from 10-day-old V8 agar cultures (Tortolero and Sequeira 1978). Contents of culture dishes were blended using tap water as a diluent. Preliminary observations indicated that hyphal fragments remaining in the resulting suspensions were non-viable and that oospores (rare) were non-germinable. An aliquot was drawn from the suspension and a hemacytometerwas used to calculate the number of sporangia per mL (Tuite 1969). Sufficient sporangia were added to soil to provide populations of 1000 or 10000 sporangia/g of soil. Preliminary experiments showed that lettuce growth was affected significantly by such densities, although death of the plants was not observed commonly.

The sporangial suspension was added to nematode-infested soil and mixed by shaking in an inflated bag. Blended V8-juice agar was added to soils containing nematodes but no Pythium. Healthy tomato roots were added to soils containing Pythium but no nematodes. The control treatment consisted of soil mixed with healthy tomato roots and blended V8 agar. Plastic pots $(12.7 \mathrm{~cm}$ diameter) were filled with these mixtures and 2-week-old lettuce seedlings were transplanted into the pots. Daily watering was made by adding water to saucers placed under each pot. Fertilization followed the same schedule as previously described.

Pots were arranged in a completely randomized design with 4 replicate-pots per treatment and one plant per pot. Five weeks after infestation of soil with sporangia, fresh and dry weights of leaves and roots, total leaf area, and numbers of nematodes in the root system were determined. The number of nematodes in roots was estimated by staining an aliquot of roots with acid fuchsin (Hussey 1985). Histological observations were made to assess the effect of 
M. hapla on colonization of roots by P. tracheiphilum. Galls and secondary roots presumed to be infected with either the fungus or the nematode alone or by both pathogens were fixed in FAA ( $13 \mathrm{~mL}$ formalin, $5 \mathrm{~mL}$ glacial acetic acid, 200 mL ethyl alcohol 50\%) embedded in paraffin, sectioned and then stained with fast green and safranin (Johansen 1940).

Plant responses to different treatments were detected using analysis of variance and orthogonal contrasts (Steel and Torrie 1980). Where main effect interactions were significant, linear and quadratic regressions of simple effects were examined. The experiment was carried out twice.

Interactions between $\boldsymbol{P}$. penetrans and $\boldsymbol{P}$. tracheiphilum. Lettuce plants were produced as described previously. Nematode populations were obtained using rye (Secale cereale L.) as a host. Soil containing $P$. penetrans (obtained from the Agriculture Canada Research Station, Vineland, Ontario) was mixed with pasteurized sandy soil. Rye seeds were spread onto the soil surface and covered with a light layer of sandy soil. Plants were kept in a greenhouse at $21 \pm 4^{\circ} \mathrm{C}$ with a 14 -h photoperiod for 4 months.

For inoculation of lettuce, infected roots from 4-month-old rye plants were lightly washed with running tap water to remove soil. A 10-g subsample of roots was placed on a Baermann funnel in a mist chamber for a 10-day extraction period, during which the number of nematodes recovered was recorded every two days. Using the estimated number of nematodes per gram of root, appropriate amounts of infected rye roots were added to soil to obtain inoculum densities of 0,937 and 4687 nematodes $/ 100 \mathrm{~cm}^{3}(0,3000$ and 15000 nematodes/10.2-cm diam. pot). These populations produced significantly different effects on lettuce growth in preliminary studies.

As for M. hapla, $P$. penetrans-infested soils were left for 2 weeks in trays to allow for root decomposition prior to adding the fungus.

A suspension of sporangia of $P$. tracheiphilum was prepared as described previously and mixed with the nematode-infested soil prior to transplanting 2-week-old lettuce seedlings. Populations of the fungus were 0,1000 and 10000 sporangia/g of soil. Results were recorded 4 weeks after infestation of soil with sporangia. The experimental design, environments, measurements and anal- yses were similar to those used for experiments with $M$. hapla.

\section{Results and discussion}

Interactions between $M$. hapla and $\boldsymbol{P}$. tracheiphilum. Growth of above ground parts of lettuce was significantly reduced by either pathogen alone. Interaction between the two organisms was significant $(P \leq 0.05)$ for leaf dry weight, but was not significant for root dry weight. Leaf dry weight and leaf area data showed similar trends, therefore only leaf dry weight data are presented. The amount of reduction presented observed with either $P$. tracheiphilum or $M$. hapla alone generally was less than that observed with both organisms present.

When $P$. tracheiphilum was present at 1000 sporangia/g, M. hapla at the 4000 and 13000 nematodes/pot densities caused successive significant reductions in leaf weight when compared to Pythium alone. These reductions followed a linear response (Table 1, Fig. 1). At 10000 sporangia/g, both linear and quadratic effects were significant $(P \leq 0.01)$. The addition of $4000 \mathrm{M}$. hapla/pot did not cause further significant reductions in leaf weight, however, the addition of 13000 nematodes/pot did result in a marked reduction $(64.6 \%)$ compared to $P y$ thium alone $(43.6 \%)$. This explains the quadratic response observed. These reductions seemed to be additive and were most likely due to the destruction of secondary roots by the fungus. Plants in soil with 10000 sporangia/g had severely damaged root systems whether the nematode was present or not. The lack of significance of the interaction between these two organisms on root dry weight is probably due to the compensatory effect of the galls and an associated increase in root growth (Fig. 2). When alone, $M$. hapla did not have a significant effect on root growth (Fig. 2A). P. tracheiphilum significantly reduced root weights in the absence of $M$. hapla, although increasing the population of sporangia from 4000 to 10000 per gram of soil had no effect (Fig. 2B).

Most studies of interactions of these two plant pathogens have used sequential inoculations. In our tests a simultaneous inoculation was used because pre-inoculation of lettuce with $M$. hapla could not be justified from an epidemiological point of view. Melendéz and Powell (1970a, 1970b) observed that $P$. ultimum does not cause significant damage to roots 
unless $M$. incognita is added 3 or 4 weeks in advance. Activity of $P$. tracheiphilum appears to be greater in the spring when prevailing temperatures are relatively low. M. hapla has an optimal temperature for plant infection of about $24^{\circ} \mathrm{C}$ (Wong and Mai 1973) although infection can occur at $12^{\circ} \mathrm{C}$ (Vrain et al. 1978). It appears that, in Québec, conditions favoring infection by the nematode are not likely to occur in the field 3 or 4 weeks prior to conditions favoring attack by $P$. tracheiphilum. Thus, simultaneous inoculations were carried out in these experiments.

Plants inoculated with the fungus alone or in combination with M. hapla were stunted. Dis-
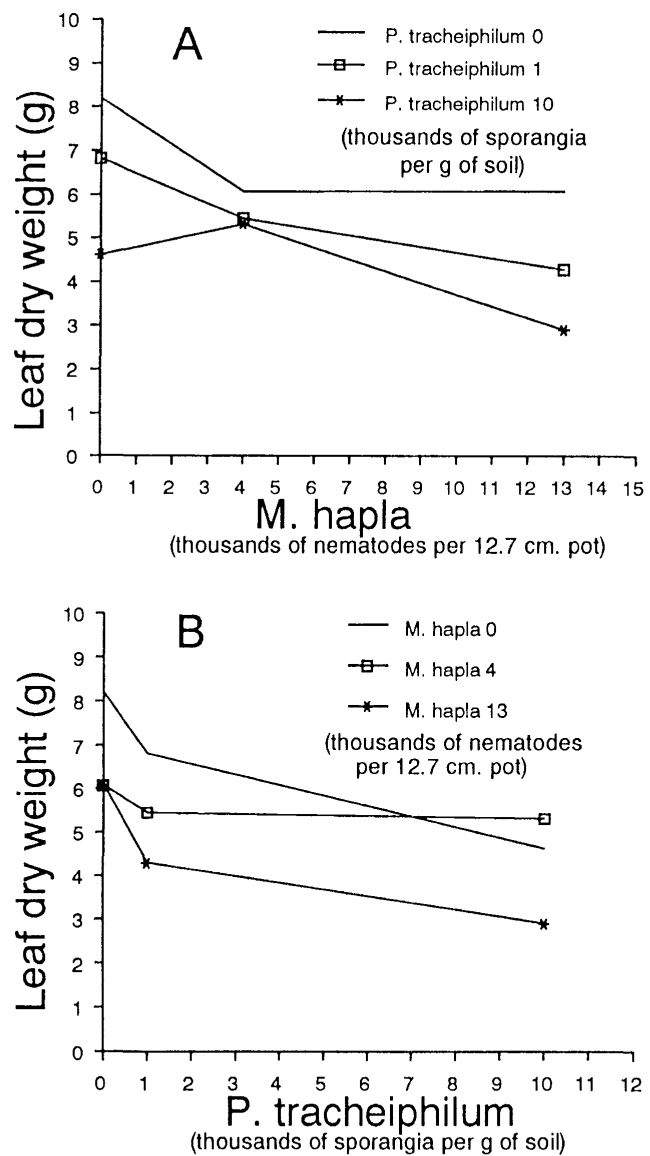

Figure 1. Leaf dry weight of lettuce plants inoculated with Pythium tracheiphilum and Meloidogyne hapla. A. Effects of $M$. hapla on dry weight for three populations of $P$. tracheiphilum. B. Effects of $P$. tracheiphilum on dry weight for three populations of $M$. hapla. Curves are lines drawn through mean values $(n=4)$ for each treatment. coloration of the vascular system of the tap root was observed only in a few plants. However, secondary roots consistently had the red-brown discoloration typically associated with $P$. tracheiphilum. When these roots were placed on agar media, the fungus was readily recovered. Plants may have been harvested before vascular discoloration became fully developed.

It also was observed that the fungus had a negative effect on populations of $M$. hapla inside the root system. Plants inoculated with only the nematode had 40 to $80 \%$ more nematodes than those inoculated with the nematode and the fungus (Table 2, Fig. 3). Several studies show that some species of soilborne fungi sup-
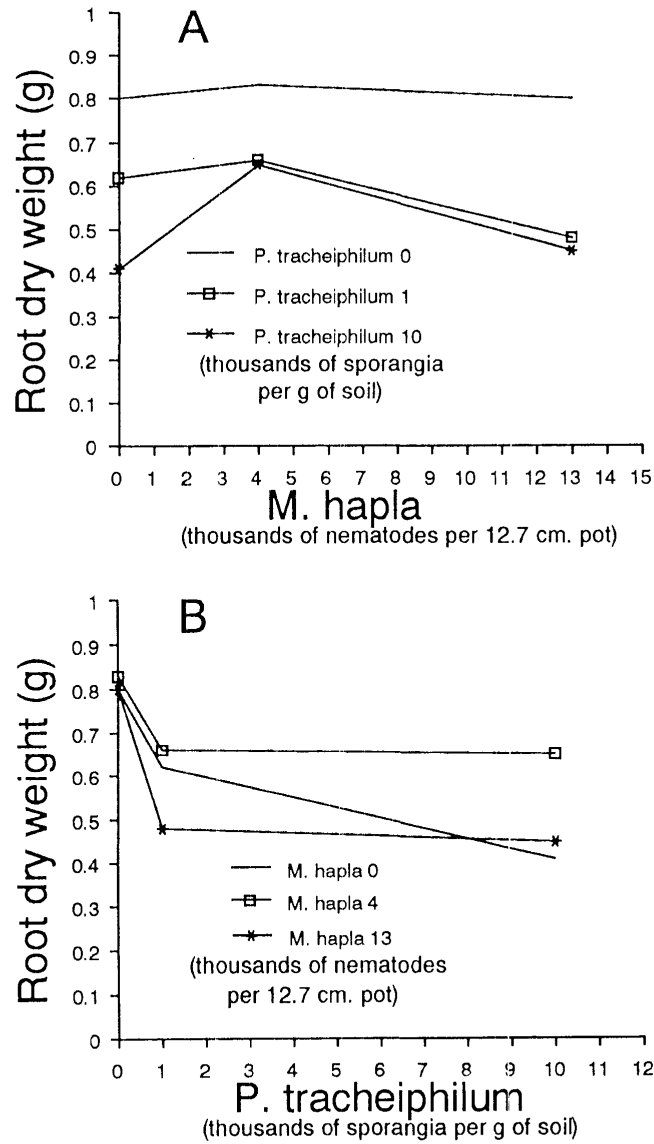

Figure 2. Root dry weight of lettuce plants inoculated with Pythium tracheiphilum and Meloidogyne hapla. A. Effects of M. hapla on dry weight for three populations of $P$. tracheiphilum. B. Effects of P. tracheiphilum on dry weight for three populations of $M$ hapla. Curves are lines drawn through mean values $(n=4)$ for each treatment. 
Table 1. Orthogonal comparisons of the effect on leaf dry weight of lettuce plants of Pythium tracheiphilum (Py) populations in the presence of Meloidogyne hapla (M) and of $M$. hapla populations in the presence of $P$. tracheiphilum

\begin{tabular}{cccc}
\hline & \multicolumn{2}{c}{ Leaf dry weight $^{\dagger}$} \\
\cline { 2 - 4 } Orthogonal comparison $^{\S}$ & $\mathrm{df}$ & Sum of squares & $P>F$ \\
\hline M in Py 0 & 2 & 0.4188 & 0.0071 \\
M Linear in Py 0 & $(1)$ & 0.2325 & 0.0158 \\
M Quadratic in Py 0 & $(1)$ & 0.1863 & 0.0291 \\
M in Py 1 & 2 & 0.5941 & 0.0014 \\
M Linear in Py 1 & $(1)$ & 0.5752 & 0.0004 \\
M Quadratic in Py 1 & $(1)$ & 0.0189 & 0.4687 \\
M in Py 10 & 2 & 0.8517 & 0.0002 \\
M Linear in Py 10 & $(1)$ & 0.6072 & 0.0003 \\
M Quadratic in Py 10 & $(1)$ & 0.2445 & 0.0136 \\
Error & 27 & 0.3646 & \\
\hline
\end{tabular}

\begin{tabular}{lccc}
\hline & \multicolumn{3}{c}{ Leaf dry weight } \\
\cline { 2 - 4 } Orthogonal comparison & df & Sum of squares & $P>F$ \\
\hline Py in M 0 & 2 & 1.0349 & 0.0001 \\
Py in Linear in M 0 & $(1)$ & 0.9605 & 0.0001 \\
Py Quadratic in M 0 & $(1)$ & 0.0744 & 0.1567 \\
Py in M 4 & 2 & 0.0560 & 0.4602 \\
Py in M 13 & 2 & 1.2561 & 0.0001 \\
Py Linear in M 13 & $(1)$ & 1.0196 & 0.0001 \\
Py Quadratic M 13 & $(1)$ & 0.2368 & 0.0150 \\
Error & 27 & 0.3646 & \\
\hline
\end{tabular}

$\S$ Py: Pythium tracheiphilum; Py $0=0$ sporangia per gram of soil; Py $1=1000$ sporangia per gram of soil; Py $10=$ 10000 sporangia per gram of soil. M: Meloidogyne hapla; $\mathrm{M} 0=0$ nematode per $12.5 \mathrm{~cm}$ pot; $\mathrm{M} 4=4000$ nematodes per $12.5 \mathrm{~cm}$ pot; $\mathrm{M} 13=13000$ nematodes per $12.5 \mathrm{~cm}$ pot.

$\dagger$ All significant leaf dry weight interactions are presented for both analyses of variance. Root dry weight interactions were not significant.

Table 2. Effect of Pythium tracheiphilum (Py) populations on numbers of Meloidogyne hapla (M) nematodes observed in lettuce roots where Py 0, Py 1 and Py 10 represent 1, 1000 amd 10000 sporangia/g soil, respectively

\begin{tabular}{lccc}
\hline Orthogonal comparison & df & Sum of squares & $P>F$ \\
\hline M in Py 0 & 2 & 16.5138 & 0.0001 \\
M Linear in Py 0 & $(1)$ & 11.1755 & 0.0001 \\
M Quadratic in Py 0 & $(1)$ & 5.3383 & 0.0001 \\
M in Py 1 & 2 & 8.4726 & 0.0001 \\
M Linear in Py 1 & $(1)$ & 3.3603 & 0.0001 \\
M Quadratic in Py 1 & $(1)$ & 5.1123 & 0.0001 \\
M in Py 10 & 2 & 11.1616 & 0.0001 \\
M Linear in Py 10 & $(1)$ & 5.8725 & 0.0001 \\
M Quadratic in Py 10 & $(1)$ & 5.2890 & 0.0001 \\
Error & 27 & 0.4250 & \\
\hline
\end{tabular}


press the development of Meloidogyne spp. (Johnson and Littrell 1970; Ryder and Crittenden 1965).

Many $M$. hapla galls from plants co-inoculated with $P$. tracheiphilum did not contain nematodes. These galls were macerated and had a red-brown discoloration. Microscopic observations revealed the presence of high numbers of sporangia and oospores in gall tissue although in general the fungus also was present in the remainder of the root system. Tips of tertiary and secondary roots also were highly colonized by the fungus and commonly contained oospores and sporangia. It has been suggested that chemical changes and accumulation of various substances in the galls may enhance the reproduction of fungi (Brodie and Cooper 1964; Powell 1971). Histological observations revealed that nematodes were not colonized by the fungus. It was not clear if the galls or tissue surrounding the galls provided additional entry points into the root system for the fungus, however, pieces of mycelium were observed more commonly in vascular vessels of galled tissue than in non-galled tissue.

Interactions between $\boldsymbol{P}$. penetrans and $\boldsymbol{P}$. tracheiphilum. A linear response was observed for the effects of both pathogens when applied alone (Figs. 4 and 5). Interactions were not significant for leaf dry weight or leaf area.

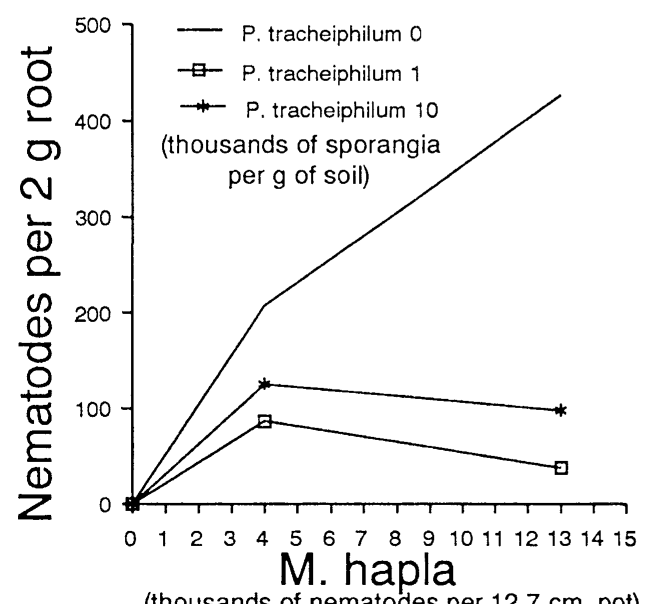

Figure 3. Effect of the presence of Pythium tracheiphilum on the number of Meloidogyne hapla nematodes observed inside lettuce roots. Curves are lines drawn through mean values $(n=4)$ for each treatment.
However, interactions for root dry weight were significant $(P \leq 0.01)$.

Reductions observed in leaf growth when Pythium was applied at a rate of 1000 sporangia/g seemed to be partially additive. Iecreases in leaf growth which occurred when nematodes were added $(21.0 \%$ at 3000 nematodes per pot and $36.6 \%$ at 15000 nematodes per pot) were higher than those for the fungus alone $(15.6 \%)$, but lower than the total of the reductions caused by each pathogen alone. When the two pathogens were acting alone, the effect on root dry weight was linear, but when the fungus popula-
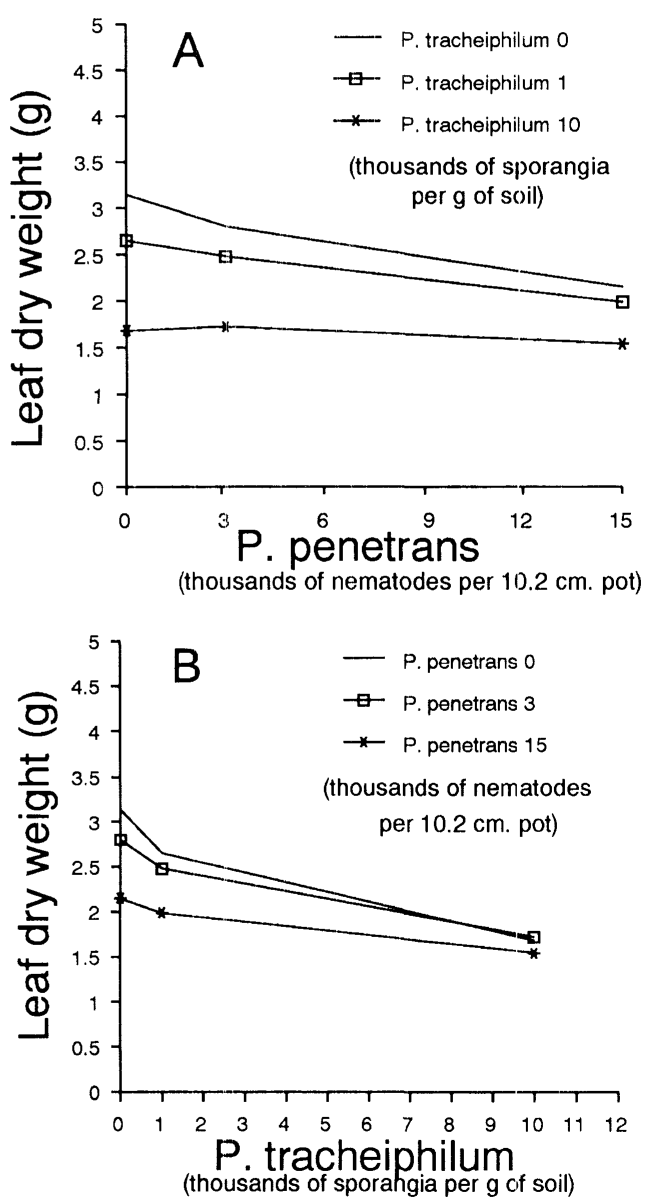

Figure 4. Leaf dry weight of lettuce plants inoculated with Pythium tracheiphilum and Pratylenchus penetrans. A. Effects of P. penetrans on dry weight for three populations of $P$. tracheiphilum. B. Effects of $P$. tracheiphilum on dry weight for three populations of $P$. penetrans. Curves are lines drawn through mean values $(n=4)$ for each treatment. 
Table 3. Orthogonal comparisons of the effect on leaf dry weight of lettuce plants of Pythium tracheiphilum (Py) populations in the presence of Pratylenchus penetrans $(\mathrm{Pr})$ and of $P$. penetrans populations in the presence of $P$. tracheiphilum

\begin{tabular}{lccc}
\hline & \multicolumn{3}{c}{ Leaf dry weight $^{\dagger}$} \\
\cline { 2 - 4 } Orthogonal comparison $^{\S}$ & df & Sum of squares & $P>F$ \\
\hline Pr in Py 0 & 2 & 0.0611 & 0.0001 \\
Pr Linear in Py 0 & $(1)$ & 0.0611 & 0.0001 \\
Pr Quadratic in Py 0 & $(1)$ & 0.0000 & 0.9829 \\
Pr in Py 1 & 2 & 0.0487 & 0.0001 \\
$\quad$ Pr Linear in Py 1 & $(1)$ & 0.0396 & 0.0001 \\
Pr Quadratic in Py 1 & $(1)$ & 0.0090 & 0.0131 \\
Pr in Py 10 & 2 & 0.0057 & 0.1259 \\
Error & 27 & 0.0345 & \\
\hline
\end{tabular}

\begin{tabular}{lccc} 
& \multicolumn{3}{c}{ Root dry weight } \\
\cline { 2 - 4 } Orthogonal comparison & df & Sum of squares & $P>F$ \\
\hline Py in Pr 0 & 2 & 0.0981 & 0.0001 \\
Py Linear in Pr 0 & $(1)$ & 0.0979 & 0.0001 \\
Py Quadratic in Pr 0 & $(1)$ & 0.0002 & 0.6965 \\
Py in Pr 3 & 2 & 0.0485 & 0.0001 \\
Py Linear in Pr 3 & $(1)$ & 0.0363 & 0.0001 \\
Py Quadratic Pr 3 & $(1)$ & 0.0122 & 0.0046 \\
Py in Pr 15 & 2 & 0.0121 & 0.0174 \\
Py Linear in Pr 15 & $(1)$ & 0.0117 & 0.0053 \\
Py Quadratic Pr 15 & $(1)$ & 0.0003 & 0.6081 \\
Error & 27 & 0.0345 & \\
\hline
\end{tabular}

$\S$ Pr: Pratylenchus penetrans; $\operatorname{Pr} 0=0$ nematode per $12.5 \mathrm{~cm}$ pot; $\operatorname{Pr} 3=3000$ nematodes per $12.5 \mathrm{~cm}$ pot; $\operatorname{Pr} 15=$ 15000 nematodes per $12.5 \mathrm{~cm}$ pot. Py: Pythium tracheiphilum; Py $0=0$ sporangia per gram of soil; Py $1=1000$ sporangia per gram of soil; Py $10=10000$ sporangia per gram of soil.

$\doteqdot$ All significant root dry weight interactions are presented for both analyses of variance. Leaf dry weight interactions were not significant.

Table 4. Effect of Pythium tracheiphilum (Py) populations on the numbers of Pratylenchus penetrans (Pr) nematodes observed in lettuce roots where Py 0, Py 1 and Py 10 represent 0,1000 and 10000 sporangia/g soil, respectively

\begin{tabular}{lccc}
\hline Orthogonal comparison & df & Sum of squares & $P>F$ \\
\hline Pr in Py 0 & 2 & 19.6612 & 0.0001 \\
Pr Linear in Py 0 & $(1)$ & 11.1696 & 0.0001 \\
Pr Quadratic in Py 0 & $(1)$ & 8.4915 & 0.0001 \\
Pr in Py 1 & 2 & 16.5655 & 0.0001 \\
Pr Linear in Py 1 & $(1)$ & 9.3155 & 0.0001 \\
Pr Quadratic in Py 1 & $(1)$ & 7.2501 & 0.0001 \\
Pr in Py 10 & 2 & 15.9446 & 0.0001 \\
Pr Linear in Py 10 & $(1)$ & 10.2686 & 0.0001 \\
Pr Quadratic in Py 10 & $(1)$ & 5.6760 & 0.0001 \\
Error & 27 & 0.2010 & \\
\hline
\end{tabular}


tion was 1000 sporangia/g and nematodes were added to the soil, a quadratic effect was significant (Table 3, Fig. 5A). This reaction suggests that the detrimental effect of one of the pathogens is somehow inhibited by the presence of the other.

When the fungus was at the 10000 sporangia/g density, the interaction for leaf dry weight appeared to be negative. The reduction in leaf dry weight from the fungus alone was $46.5 \%$ and, when combined with 3000 or 15000 nematodes/pot, the growth reductions were $45.2 \%$ and $51.0 \%$, respectively. Addition of

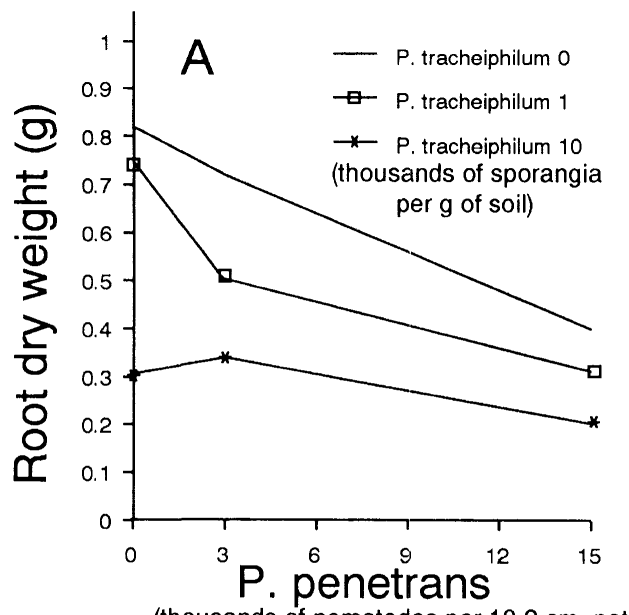

(thousands of nematodes per $10.2 \mathrm{~cm}$. pot)

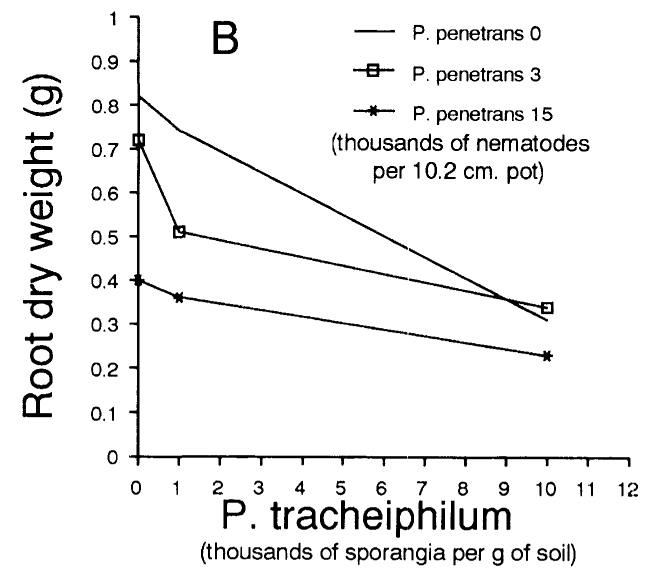

Figure 5. Root dry weight of lettuce plants inoculated with Pythium tracheiphilum and Pratylenchus penetrans. A. Effects of P. penetrans on dry weight for three populations of $P$. tracheiphilum. B. Effects of $P$. tracheiphilum on dry weight for three populations of $P$. penetrans. Curves are lines drawn through mean values $(n=4)$ for each treatment.

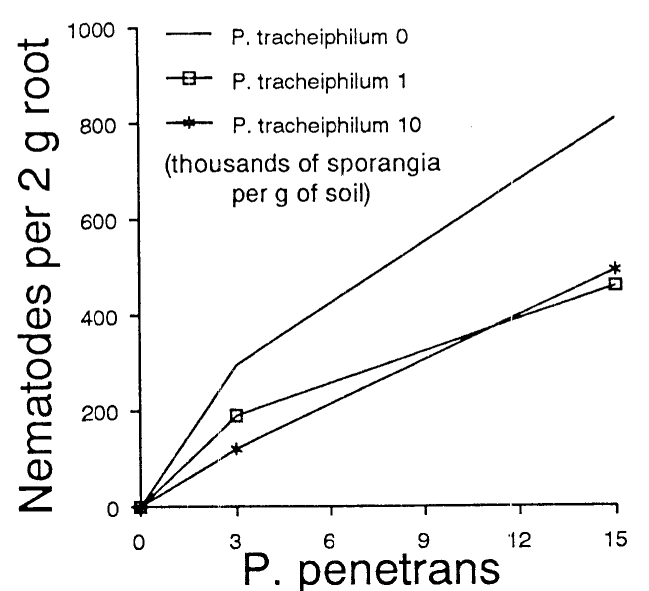

(thousands of nematodes per $10.2 \mathrm{~cm}$. pot)

Figure 6. Effect of the presence of Pythium tracheiphilum on the number of Pratylenchus penetrans nematodes observed inside lettuce roots. Curves are ines drawn through mean values $(n=4)$ for each treatment.

nematodes, at either density, did not increase significantly the reduction of leaf or root dry weight when $P$. tracheiphilum was at its highest density (Figs. 4 and 5).

It could not be determined whether the absence of an additive effect at 10000 sporangia/g occurred because the pathogens were occupying the same space in the root system or because activity of one of them was being suppressed by the other. While most reports indicate that populations of migratory nematodes usually are increased by the presence of different soil fungi, it has been noted that populations of Pratylenchus in the presence of Pythium spp. tend to decline. Holtzmann and Santo (1971) noted that Pratylenchus zeae Graham increased by 220 -fold when used to inoculate sugarcane, but increased only 8 -fold when the plant was inoculated with both nematode and Pythium graminicola Subramanian.

$P$. penetrans populations in roots were significantly reduced in the presence of the fungus (Table 4, Fig. 6). This could explain the lack of additional leaf reduction when nematodes were combined with Pythium, especially when the latter was at a high density.

Differences observed in the reaction of the plants to the two species of nematode in the presence of $P$. tracheiphilum are likely due to differences in the way these species attack 
plants. M. hapla-infected plants were harvested after five weeks while $P$. penetrans-infected plants were harvested after only four weeks, however, it seems unlikely that the additional week would have a major effect on differences between treatments.

Small feeder roots appeared to be destroyed from the combined action of the nematodes and the fungus. Mycelium, sporangia, and oospores of $P$. tracheiphilum were present in all discolored tissues of secondary roots.

\section{Conclusions}

Plant parasitic nematodes did not appear to have a marked effect on penetration of roots by the fungus. However, large numbers of Pythium reproductive structures were observed in $M$. hapla-infected tissue. The fungus had negative effects on root populations of both nematodes.

An additive interaction was shown between $M$. hapla and P. tracheiphilum and it appears that when populations of Pythium are low, the presence of $M$. hapla can have a significant effect on lettuce growth. On the other hand, high inoculum densities of $M$. hapla are needed in order to cause significant further reductions in plant growth when populations of Pythium also are high. This latter observation may be related to the detrimental effect this fungus has on nematode populations.

Interactions between $P$. penetrans and $P$. tracheiphilum were less clear. No further reduction in lettuce growth was observed when both pathogens were present at the highest populations. When the fungus was at its lowest concentration, plants appeared to have a more marked reaction to the presence of both pathogens. This could be due to reduced inhibition of the nematode when low populations of P. tracheiphilum are present.

Our results suggest that plant parasitic nematodes, in particular M. hapla, may increase the severity of lettuce wilt caused by $P$. tracheiphilum. Further studies are required in order to determine how colonization by the fungus is affected in time and space by the presence of the nematode and whether or not decreases in nematode populations in the presence of $P$. tracheiphilum are due simply to competition for a specific site in the root system or to some physiological change occurring in the host.
We thank Dr. J. W. Townshend for providing a $P$. penetrans population, S. Monette for technical assistance and Dr. M. Fanous for statistical advice. These studies were supported by Le Conseil des Recherches en Pêche et Agro-alimentaire du Québec.

Barker, K.R. 1985. Nematode extraction and bioassays. Part I. Chapter 2. Pages 19-35 in K.R. Barker, C.C. Carter, and J.N. Sasser (eds.), An advanced treatise on Meloidogyne. Vol. II. Methodology. North Carolina State University, Raleigh.

Brodie, B.B., and W.E. Cooper. 1964. Relation of parasitic nematodes to postemergence damping-off of cotton. Phytopathology 54: 1023-1027.

Holtzmann, V., and G.S. Santo. 1971. Effect of temperature on the interrelationship of Pratylenchus zeae and Pythium graminicola on sugarcane. Phytopathology 61: 1321 (Abstract).

Hussey, R.S. 1985. Staining nematodes in plant tissue. Pages 197-199 in B.M. Zuckerman, W.F. Mai, and M.B. Harrison (eds.), Plant nematology, laboratory manual. Univ. of Massachusetts Agric. Exp. Stn.

Johansen, D.A. 1940. Plant microtechnique. McGrawHill Book Co., Inc., New York. 523 pp.

Johnson, A.W., and R.H. Littrell. 1970. Pathogenicity of Pythium aphanidermatum to Chrysanthemum in combined inoculations with Belonolaimus longicaudatus or Meloidogyne incognita. J. Nematol. 2: 255259.

Matta, A. 1965. Una malatia della Lattuga prodotta da una nuova specie di Pythium. Phytopathol. Mediterr. 4: 48-53.

Melendéz, P.L., and N.T. Powell. 1970a. Histological studies of the Pythium root knot nematode complex in tobacco. Phytopathology 60: 1303 (Abstract).

Melendéz, P.L., and N.T.Powell. 1970b. The influence of Meloidogyne on root decay in tobacco caused by Pythium and Trichoderma. Phytopathology 60: 1348 (Abstract).

Powell, N.T. 1971. Interaction between nematodes and fungi: a disease complex. Annu. Rev. Phytopathol. 9: 253-274.

Reeleder, R.D., and F. Charbonneau. 1987. Incidence and severity of diseases caused by Botrytis cinerea, Pythium tracheiphilum, and Sclerotinia spp. on lettuce in Québec, 1985-86. Can. Plant Dis. Surv. 67: 45-46.

Reeleder, R.D., S. Bergeron, and M. McLean. 1985. Lettuce wilt in Québec caused by Pythium tracheiphilum: pathogenicity, incidence, and implications for fungicide application. Phytoprotection 66: 176 (Abstract).

Ryder,H.W., and H.W. Crittenden. 1965. Relationship of Meloidogyne acrita and Plasmodiophora brassicae in cabbage roots. Phytopathology 55: 506 (Abstract).

Steel, R.G.D., and J.H. Torrie. 1980. Principles and procedures of statistics: a biometrical approach, 2nd ed. McGraw-Hill, Inc., New York. 633 pp.

Tortolero, O., and L. Sequeira. 1978. A vascular wilt and leaf blight disease of lettuce in Wisconsin caused by a new strain of Pythium tracheiphilum. Plant Dis. Rep. 62: 616-620.

Tuite, J. 1969. Plant pathological methods. Burgess Publishing Co., Minneapolis. 239 pp. 
Vrain, T.C., and M. Dupré. 1982. Distribution des nématodes phytoparasites dans les sols maraîchers du sud-ouest de Québec. Phytoprotection 63: 79-85.

Vrain, T.C., K.R. Barker, and G.I. Holtzman. 1978. Influence of low temperature on rate of development of Meloidogyne incognita and M. hapla larvae. J. Nematol. 10: 166-171.
Wong, T.K., and W.F. Mai. 1973. Pathogenicity of Meloidogyne hapla to lettuce as affected by inoculum level, plant age at inoculation and temperature. J. Nematol. 5: 126-129. 